\title{
Incomplete Kawasaki Disease in an Elderly Man
}

\section{Gilles Safa Clémence Saillard Laure Darrieux}

Department of Dermatology, Centre Hospitalier de Saint-Brieuc, Saint-Brieuc, France

\section{Key Words}

Incomplete Kawasaki disease · Adult · Diagnosis

\begin{abstract}
Kawasaki disease (KD) is a systemic vasculitis of unknown etiology, affecting predominantly young children. Here, we describe an unusual case of a 75-year-old man with several unique features of incomplete KD. Healthcare professionals should therefore be aware of the importance of considering KD at any age, even among elderly individuals. This case also highlights the usefulness of the algorithm proposed for children to diagnose incomplete KD in adults.
\end{abstract}

\section{Introduction}

Kawasaki disease (KD) is an acute systemic vasculitis of unknown cause that occurs primarily in children and rarely in adults [1]. In the absence of specific laboratory tests, the diagnosis of KD can be challenging, especially in adults. We report an unusual case of an elderly man with several unique features of incomplete KD.

\section{Case Presentation}

A 75-year-old white man was admitted to our hospital for a 3-week history of fever and poor general condition. His past medical history included hypertension, hyperlipidemia, myocardial infarction, and a coronary artery bypass graft surgery 2 years ago. The patient denied any recent changes in medications. On admission, the patient was febrile $\left(39^{\circ} \mathrm{C}\right)$, and physical examination revealed bilateral nonpurulent conjunctivitis, red and cracked lips (fig. 1), and slightly edematous erythema with desquamation of the hands and feet (fig. 2a, b). Cervical, axillary and inguinal adenopathy was absent. There were no other abnormal physical examination findings.

Laboratory tests revealed anemia (hemoglobin $8.5 \mathrm{~g} / \mathrm{dl}$ ), hypoalbuminemia $(2.6 \mathrm{~g} / \mathrm{dl})$, elevated erythrocyte sedimentation rate (ESR) and C-reactive protein (CRP) $(83 \mathrm{~mm} / \mathrm{h}$ and $100.3 \mathrm{mg} / \mathrm{l}$, respectively), elevated alanine aminotransferase ( $56 \mathrm{IU} / \mathrm{l}$; normal <40), and sterile leukocyturia $(30$ cells $/ \mu \mathrm{l}$ ). Blood and urine cultures were negative. Serological assays for human immunodeficiency 
virus, hepatotropic viruses, Epstein-Barr virus, cytomegalovirus, and antinuclear antibodies were negative. Chest radiography and echocardiography were normal. Based on these findings, a diagnosis of incomplete KD was strongly suspected. The patient was subsequently treated with an intravenous immunoglobulin infusion ( $1 \mathrm{~g} / \mathrm{kg}$ for 2 days) and high-dose aspirin ( $3 \mathrm{~g} /$ day). The fever remitted within 3 days, and within 1 week, the laboratory abnormalities returned to normal and mucocutaneous lesions improved dramatically. Low-dose aspirin, which the patient had taken since his bypass surgery, was then restarted. The patient was discharged and instructed to follow up with his referring cardiologist.

\section{Discussion}

KD is defined as the presence of a fever for $\geq 5$ days and $\geq 4$ of the 5 major clinical features: conjunctivitis, oral mucosal changes, polymorphous rash, palmoplantar erythema with desquamation, and cervical lymphadenopathy [1]. Incomplete KD refers to patients who do not fulfill the classic criteria of $\geq 4$ of the 5 findings and in whom alternative diagnoses have been ruled out [2]. In adults, the main differential diagnoses are drug hypersensitivity reaction and toxic shock syndrome [3]. The higher prevalence of coronary artery lesions in patients with incomplete KD reflects difficulties in diagnosis and delays in treatment [4]. Although adults are less frequently affected by coronary aneurysms compared with children ( 5 vs. $20 \%$, respectively), establishing the diagnosis of incomplete KD and initiating treatment is essential [3]. In 2004, a multidisciplinary committee of experts proposed an algorithm to diagnose incomplete KD in children [5]. For pediatric patients with a fever for $\geq 5$ days and $<4$ classical criteria of KD, laboratory tests, including CRP and ESR, should be obtained. In patients with elevated CRP ( $\geq 30 \mathrm{mg} / \mathrm{l}$ ) and/or ESR ( $\geq 40 \mathrm{~mm} / \mathrm{h}$ ) levels who fulfill $\geq 3$ supplemental laboratory criteria [including albumin $\leq 3.0 \mathrm{~g} / \mathrm{dl}$, anemia, elevation of alanine aminotransferase, $\geq 450,000 / \mathrm{mm}^{3}$ platelets after 7 days, white blood count $\geq 15,000 / \mathrm{mm}^{3}$, and sterile pyuria ( $\geq 10$ cells/high-power field)], intravenous immunoglobulin and aspirin should be instituted and echocardiography should be performed.

Our case emphasizes the importance of considering KD at any age, even among elderly individuals. This case also highlights the usefulness of the algorithm proposed for children to diagnose incomplete KD in adults.

\section{Disclosure Statement}

The authors have no conflicts of interest to disclose. 


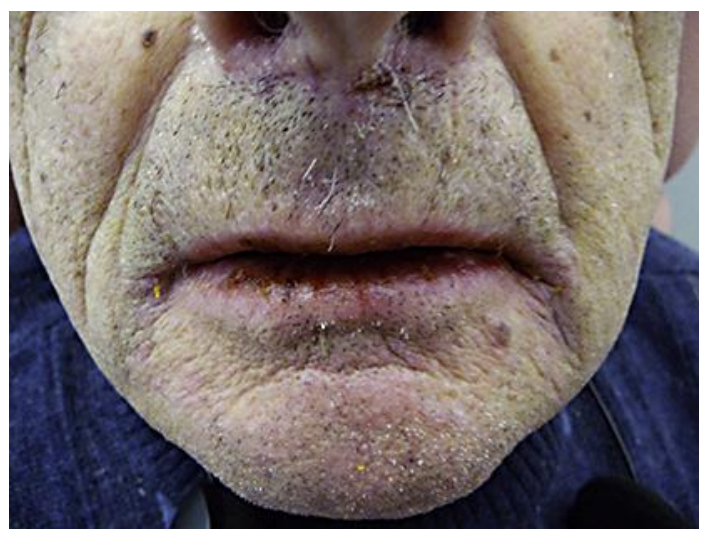

Fig. 1. Cracked, red lips.
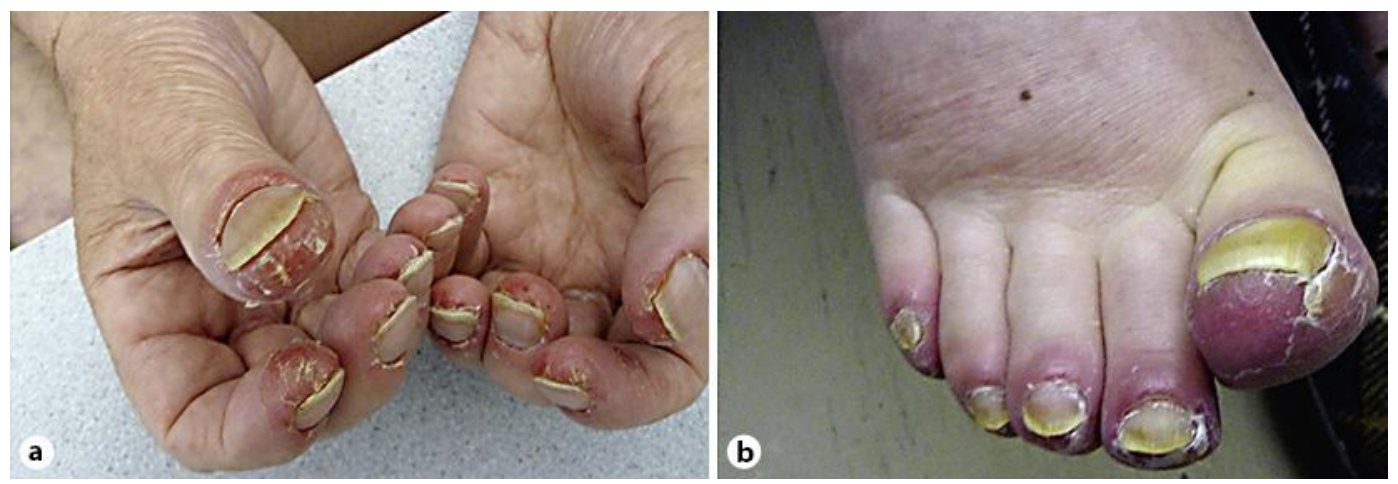

Fig. 2. a, b Erythema with periungual desquamation of the fingers and toes.

\section{References}

-1 Newburger JW, Takahashi M, Burns JC, Beiser AS, Chung KJ, Duffy CE, Glode MP, Mason WH, Reddy V, Sanders SP, et al: The treatment of Kawasaki syndrome with intravenous gamma globulin. N Engl J Med 1986;315:341-347.

-2 Burns JC, Glodé MP: Kawasaki syndrome. Lancet 2004;364:533-544.

-3 Gomard-Mennesson E, Landron C, Dauphin C, Epaulard O, Petit C, Green L, Roblot P, Lusson JR, Broussolle C, Sève P: Kawasaki disease in adults: report of 10 cases. Medicine (Baltimore) 2010;89:149_ 158.

4 Sudo D, Monobe Y, Yashiro M, Mieno MN, Uehara R, Tsuchiya K, Sonobe T, Nakamura Y: Coronary artery lesions of incomplete Kawasaki disease: a nationwide survey in Japan. Eur J Pediatr 2012;171:651-656.

5 Newburger JW, Takahashi M, Gerber MA, et al: Diagnosis, treatment, and long-term management of Kawasaki disease: a statement for health professionals from the Committee on Rheumatic Fever, Endocarditis and Kawasaki Disease, Council on Cardiovascular Disease in the Young, American Heart Association. Circulation 2004;110:2747-2771. 